\title{
Membrane deformation and separation
}

\section{Rainer Beck ${ }^{1}$, Britta Bruegger ${ }^{2}$ and Felix T Wieland ${ }^{2 *}$}

\author{
Addresses: ${ }^{1}$ Department of Cell Biology, Yale University School of Medicine, 333 Cedar Street New Haven, CT 06520, USA; ${ }^{2}$ Heidelberg University \\ Biochemistry Center (BZH), Im Neuenheimer Feld 328, D-69120 Heidelberg, Germany \\ *Corresponding author: Felix T Wieland (felix.wieland@bzh.uni-heidelberg.de) \\ Fl000 Biology Reports 2010, 2:35 (doi:10.34I0/B2-35)
}

The electronic version of this article is the complete one and can be found at: http://f1000.com/reports/biology/content/2/35

\begin{abstract}
Biological membranes are highly dynamic (e.g., during cell division, organelle biosynthesis, vesicular transport, and neurotransmitter release). They can be shaped into protein-coated transport vesicles or tubules and undergo regulated fusion. The life of transport vesicles depends on highly specific and tightly regulated protein machineries, which not only shape the donor membrane into nascent budding structures but also help to overcome the energy barrier to break the bilayers apart in order to pinch off nascent vesicles. Ultimately, vesicular membranes have to fuse with a target lipid bilayer, a process that again requires remodeling. Here, we highlight recent insights into mechanisms that lead to membrane deformation in the process of vesicular budding.
\end{abstract}

\section{Introduction and context}

Mechanisms underlying membrane deformation are highlighted in numerous recent reviews [1-16]. Various modes of phospholipid bilayer deformation were classified by McMahon and Gallop [5]. These include stereochemical properties of lipid building blocks or conformations of transmembrane proteins. In addition, the organization of the cytoskeleton can cause membrane deformation. In general, sculpting of membranes is assumed to be achieved by membrane scaffolding proteins, such as vesicular coats (coatomer for coat protein [COP]I vesicles and Sec 23/24 and Sec 13/31 for COPII vesicles) or clathrin and adaptor complexes for clathrin-coated vesicles (CCVs), or by amphipathic helices of proteins that insert into and increase the area of one leaflet of the bilayer (or by both).

The molecular mechanisms underlying budding of carrier vesicles in endocytosis or biosynthetic transport pathways are the focus of molecular cell biological research at present. These pathways employ GTPases that subsequently can recruit cytosolic coat protein complexes. The GTPase dynamin serves the generation of endocytic vesicles in combination with the adapter protein complex AP2 and clathrin [17]. In contrast, biosynthetic transport vesicles employ small GTPases Sar1p and the coat complexes Sec23/24 and Sec13/31 for COPII vesicles and Arf for COPI vesicles and various CCVs - in combination with coatomer (for COPI) or adapter complexes AP1, 3, and 4 (for CCV).

\section{Major recent advances}

Dynamin-mediated fission was thought to require a power stroke generated by a concerted conformational change in assembled dynamin and triggered by rapid GTP hydrolysis $[18,19]$. However, more recent studies demonstrated that dynamin assemblies stabilize highly curved templates [20] and that fission requires cycles of GTP hydrolysis [21]. During these cycles, the underlying membrane undergoes squeezing and relaxation, resulting in the stochastic generation of a hemifission intermediate assumed to cause fission. Thus, cycles of membrane binding and GTP hydrolysis-dependent dissociation were shown to be necessary for dynamincatalyzed membrane fission (reviewed in [22]). Another recent study showed that dynamin nucleation, and hence membrane deformation, occurs preferably at sites of high local curvature [23]. 
In analogy to dynamin, Sar1 was found to induce membrane curvature on liposomal membranes [24], and in more recent work, such a role has been reported for Arf1 [25-27]. This surface activity, however, does not require GTP hydrolysis. A minimal machinery consisting of liposomes, Arf1, and coatomer has been described to be sufficient for COPI reconstitution in vitro $[28,29]$ in the presence of non-hydrolyzable GTP analogs. While additional factors, such as Arf-GTPase-activating protein 1, were reported to be required for the release of vesicles [30], this finding was recently challenged [31].

Which mechanism then would apply for the release of a budded COPI vesicle? As vesicle separation is observed in minimal reconstituted liposomal systems [29,32,33], it is basically the coat protein or the small GTPase or both that catalyze the scission reaction. Indeed, Lee et al. [24] have observed that, although a truncated form of Sar1p supports bud formation in the COPII system, the GTPase, when lacking its amphiphatic helix, lost the ability to deform the membrane. As a consequence, separation of the nascent vesicle was inhibited [24]. This opens a possibility that in the early secretory pathway, the small GTPases, in addition to recruiting coat proteins, have a role in membrane fission. Along these lines, free Arf1-GTP has been recently reported to preferentially localize to areas of low membrane curvature [34] when GTP-hydrolysis is stimulated by the curvature-sensitive ArfGAP1 enzyme [35]. Thus, Arf1 is likely to reside at sites where fission finally occurs, at the neck of the nascent bud.

\section{Future directions}

Models for the molecular mechanism of membrane separation have been forwarded on the basis of the assumption that the protein involved in a scission reaction would stabilize a transition state. Conceptually, it may be useful to consider models in which an unstable, energetically unfavorable transition state that can be relaxed by membrane separation is generated. For the small GTPases, this would imply that they must have affinity to membranes strong enough to remain in a membrane at sites of increasing negative curvature, as represented by the growing neck of a maturing bud. To avoid escape from energetically unfavorable sites, the GTPase would need to be stably anchored to the bud's coat. In the case of COPI vesicles, Arf1 is tightly bound by multiple specific interaction sites with its covering sheet of polymerized coatomer [36], and thus firmly kept in place even at a location of negative curvature, which forms in the bud neck and is energetically unfavorable to accommodate the small GTPase. Scission of a bud would then occur in case the energy barrier for spontaneous fusion of adjacent membranes in the neck was lower than that for an escape of Arf1 from high-energy sites. Arf1 was recently described to dimerize upon activation with GTP, and an Arf1 mutant unable to dimerize did not support COPI vesicle formation [25]. Thus, it seems attractive to speculate that the avidity to bind to membranes gained by dimerization of small GTPases adds to the mechanisms of membrane separation. It will be exciting in the future to experimentally challenge this hypothesis.

\section{Abbreviations \\ $\mathrm{CCV}$, clathrin-coated vesicle; $\mathrm{COP}$, coat protein.}

\section{Competing interests}

The authors declare that they have no competing interests.

\section{Acknowledgments}

We would like to thank the German Research Council for funding our research (SFB 638, A10).

\section{References}

I. Krauss M, Haucke V: Shaping membranes for endocytosis. Rev Physiol Biochem Pharmacol 2009, [Epub ahead of print].

2. Campelo F, Fabrikant G, McMahon HT, Kozlov MM: Modeling membrane shaping by proteins: focus on EHD2 and N-BAR domains. FEBS Lett 2010, 584:1830-9.

3. Lundmark R, Carlsson SR: Driving membrane curvature in clathrin-dependent and clathrin-independent endocytosis. Semin Cell Dev Biol 2010, 21:363-70.

4. Itoh T, Takenawa T: Mechanisms of membrane deformation by lipid-binding domains. Prog Lipid Res 2009, 48:298-305.

5. McMahon HT, Gallop JL: Membrane curvature and mechanisms of dynamic cell membrane remodelling. Nature 2005, 438:590-6.

6. Zimmerberg J, Kozlov MM: How proteins produce cellular membrane curvature. Nat Rev Mol Cell Biol 2006, 7:9-19.

7. Itoh T, De Camilli P: BAR, F-BAR (EFC) and ENTH/ANTH domains in the regulation of membrane-cytosol interfaces and membrane curvature. Biochim Biophys Acta 2006, I 76 I:897912.

8. Sens $\mathrm{P}$, Johannes L, Bassereau P: Biophysical approaches to protein-induced membrane deformations in trafficking. Curr Opin Cell Biol 2008, 20:476-82.

9. Campelo F, McMahon HT, Kozlov MM: The hydrophobic insertion mechanism of membrane curvature generation by proteins. Biophys J 2008, 95:2325-39.

10. Drin G, Antonny B: Amphipathic helices and membrane curvature. FEBS Lett 2010, 584:1840-7.

II. Bhatia VK, Hatzakis NS, Stamou D: A unifying mechanism accounts for sensing of membrane curvature by BAR domains, amphipathic helices and membrane-anchored proteins. Semin Cell Dev Biol 2010, 2 I:381-90.

12. Liu J, Sun Y, Drubin DG, Oster GF: The mechanochemistry of endocytosis. PLoS Biol 2009, 7:el000204.

13. Frost A, Unger VM, De Camilli P: The BAR domain superfamily: membrane-molding macromolecules. Cell 2009, I37:191-6.

14. Shibata Y, Hu J, Kozlov MM, Rapoport TA: Mechanisms shaping the membranes of cellular organelles. Annu Rev Cell Dev Biol 2009, 25:329-54

15. Suetsugu S, Toyooka K, Senju Y: Subcellular membrane curvature mediated by the BAR domain superfamily proteins. Semin Cell Dev Biol 2010, 21:340-9. 
16. Masuda M, Mochizuki N: Structural characteristics of BAR domain superfamily to sculpt the membrane. Semin Cell Dev Biol 2010, 21:391-8.

17. McMahon HT, Mills IG: COP and clathrin-coated vesicle budding: different pathways, common approaches. Curr Opin Cell Biol 2004, 16:379-9I.

18. Hinshaw JE, Schmid SL: Dynamin self-assembles into rings suggesting a mechanism for coated vesicle budding. Nature 1995, 374:190-2.

19. Roux A, Uyhazi K, Frost A, De Camilli P: GTP-dependent twisting of dynamin implicates constriction and tension in membrane fission. Nature 2006, 44I:528-31.

FI000 Factor 7.0 Must Read

Evaluated by Mark Lemmon 15 May 2006, Adam Linstedt 17 May 2006, Volker Haucke 24 May 2006, Beverly Wendland 31 May 2006, Peter McPherson 07 Jun 2006

20. Bashkirov PV, Akimov SA, Evseev Al, Schmid SL, Zimmerberg J, Frolov VA: GTPase cycle of dynamin is coupled to membrane squeeze and release, leading to spontaneous fission. Cell 2008, 135:1276-86.

FI000 Factor 6.4 Must Read

Evaluated by Elizabeth Smythe 16 Jan 2009, Beverly Wendland 07 Apr 2009

21. Pucadyil TJ, Schmid SL: Real-time visualization of dynamincatalyzed membrane fission and vesicle release. Cell 2008, 135: 1263-75.

FI000 Factor 6.6 Must Read

Evaluated by Elizabeth Smythe 16 Jan 2009, Beverly Wendland 07 Apr 2009, Felix Wieland 17 Apr 2009

22. Pucadyil TJ, Schmid SL: Conserved functions of membrane active GTPases in coated vesicle formation. Science 2009, 325:1217-20.

23. Roux A, Koster G, Lenz M, Sorre B, Manneville JB, Nassoy P, Bassereau $P$ : Membrane curvature controls dynamin polymerization. Proc Natl Acad Sci U S A 2010, 107:4141-6.

24. Lee MC, Orci L, Hamamoto S, Futai E, Ravazzola M, Schekman R: Sarlp $\mathbf{N}$-terminal helix initiates membrane curvature and completes the fission of a COPII vesicle. Cell 2005, I 22:605-I7.

FI000 Factor 9.6 Exceptional

Evaluated by Anne Spang 16 Sep 2005, David Stephens 19 Jan 2006

25. Beck R, Sun Z, Adolf F, Rutz C, Bassler J, Wild K, Sinning I, Hurt E, Brügger $B$, Béthune J, Wieland F: Membrane curvature induced by ArfI-GTP is essential for vesicle formation. Proc Natl Acad Sci U S A 2008, 105:1|731-6.

FI000 Factor 6.0 Must Read

Evaluated by David Stephens 20 Aug 2008
26. Krauss M, Jia JY, Roux A, Beck R, Wieland FT, De Camilli P, Haucke V: ArfI-GTP-induced tubule formation suggests a function of Arf family proteins in curvature acquisition at sites of vesicle budding. J Biol Chem 2008, 283:277I7-23.

27. Lundmark R, Doherty GJ, Vallis Y, Peter BJ, McMahon HT: Arf family GTP loading is activated by, and generates, positive membrane curvature. Biochem J 2008, 414:189-94.

28. Reinhard C, Schweikert M, Wieland FT, Nickel W: Functional reconstitution of COPI coat assembly and disassembly using chemically defined components. Proc Natl Acad Sci U S A 2003, 100:8253-7.

29. Spang A, Matsuoka K, Hamamoto S, Schekman R, Orci L: Coatomer, ArfIp, and nucleotide are required to bud coat protein complex I-coated vesicles from large synthetic liposomes. Proc Natl Acad Sci U S A 1998, 95: I I 199-204.

30. Yang JS, Lee SY, Gao M, Bourgoin S, Randazzo PA, Premont RT, Hsu WW: ARFGAPI promotes the formation of COPI vesicles, suggesting function as a component of the coat. J Cell Biol 2002, I 59:69-78.

FI000 Factor 6.4 Must Read

Evaluated by Rainer Duden 24 Oct 2002, Michael Roth 27 Nov 2002

31. Beck R, Adolf F, Weimer C, Bruegger B, Wieland FT: ArfGAPI activity and COPI vesicle biogenesis. Traffic 2009, 10:307-I5.

32. Matsuoka K, Orci L, Amherdt M, Bednarek SY, Hamamoto S, Schekman R, Yeung T: COPII-coated vesicle formation reconstituted with purified coat proteins and chemically defined liposomes. Cell 1998, 93:263-75.

33. Bremser $M$, Nickel $W$, Schweikert $M$, Ravazzola $M$, Amherdt $M$, Hughes CA, Söllner TH, Rothman JE, Wieland FT: Coupling of coat assembly and vesicle budding to packaging of putative cargo receptors. Cell 1999, 96:495-506.

34. Ambroggio E, Sorre B, Bassereau P, Goud B, Manneville JB, Antonny B: ArfGAPI generates an Arfl gradient on continuous lipid membranes displaying flat and curved regions. EMBO J 2010, 29:292-303.

FI000 Factor 6.0 Must Read Evaluated by Catherine Jackson 04 Dec 2009

35. Bigay J, Gounon P, Robineau S, Antonny B: Lipid packing sensed by ArfGAPI couples COPI coat disassembly to membrane bilayer curvature. Nature 2003, 426:563-6.

FI000 Factor 8.2 Exceptional

Evaluated by Karin Romisch 09 Dec 2003, Alfred Wittinghofer 12 Mar 2004, Rainer Pepperkok I4 May 2004

36. Sun Z, Anderl F, Frohlich K, Zhao L, Hanke S, Brugger B, Wieland F, Bethune J: Multiple and stepwise interactions between coatomer and ADP-ribosylation factor-I (ArfI)-GTP. Traffic 2007, 8:582-93. 